2) M.LJ. Mihailovich, Z. Cekovic. The Chemistry of Hydroxyl Group, S. Patai, Ed,. p. 505, Interscience Pub. London, (1971).

3) P.D. McDonald, G.A. Hamilton Oxidation in Organic Chemistry, Part B, W.S. Trahanovsky Ed., Academic Press, New York, (1973).
4) F. J. Vermillion, I.A. Pearl, J. Electrochem. Soc. 111, 1392 (1964).

5) C. Iwakura, M. Tsunaga, H. Tamura, Electrochim. Acta 17, 1391 (1972).

6) V.D. Parker, A. Ronlan, J. Electroanal. Chem. 30,502 (1971).

\title{
The Anodic Evolution of Oxygen on Platinum Oxide Electrode in Acidic Solutions*
}

\author{
Chiaki IWAKURA**, Ken--ichi FUKUDA** and Hideo TAMURA**
}

\begin{abstract}
The anodic evolution of oxygen on a platinum oxide electrode in acidic solutions was investigated by polarization measurements in the quasi-steady state. The overvoltage data were reproducible on this electrode. The observed mechanistic parameters were $b_{\mathrm{a}}=0.113 \mathrm{~V} / \mathrm{dec}, b_{\mathrm{c}}=-0.124 \mathrm{~V} / \mathrm{dec}, \nu=$ 3.9, $(\partial \log i / \partial \mathrm{pH})_{E}=0.0$ and $(\partial E / \partial \mathrm{pH})_{i}=-0.00 \mathrm{~V}$. The overall current density for oxygen generation was expressed as $i=n F k \exp (\mathrm{FE} / 2 R T)$ and was controlled by the step of the primary water discharge. The activation energy was evaluated to be 12 to $13 \mathrm{kcal} / \mathrm{mole}$ that was practically independent of overpotential. It was also suggested that the anodic behavior of the platinum oxide was similar to that of the platinum oxide films produced by plolonged anodization.
\end{abstract}

\section{Introduction}

It has already been known that the oxide film on the surface of platinum plays an important role in the anodic evolution of oxygen, the rate of which is greatly affected by the pretreatment of the electrode. Schultze and Vetter ${ }^{1}$ and Damjanovic et al. ${ }^{2)}$ have reported the linear decrease of $\log i$ with increasing thickness of the oxide film. The former workers regarded non-hydrated $\mathrm{PtO}$ as the oxide layer. The surface state of platinum anode has gradually been clarified by means of in situ measurements such as ellipsometry. However, the composition of the oxide has not yet been determined.

In the previous paper ${ }^{3)}$, the oxygen evolution reaction in alkaline solutions has been investigated on a platinum oxide electrode prepared by a thermal decomposition method. In the present

\footnotetext{
*Presented at the 42nd Annual Meeting of the Electrochemical Society of Japan, Yamanashi, April, 1975.

**Department of Applied Chemistry, Faculty of Engineering, Osaka University (Yamadakami, Suita, Osaka)
}

study, the same kind of the electrode was used for oxygen generation in acidic solutions, and the reaction mechanism was discussed by comparing with the results obtained in alkaline solutions.

\section{Experimental}

The experimental procedures were almost the same as described in the previous paper ${ }^{3}$.

The test electrode or the titanium-supported platinum oxide electrode was prepared by thermal decomposition of chloroplatinic acid on a titanium plate with an amount of up to $10^{-5} \mathrm{~mol} /$ $\mathrm{cm}^{2}$. The platinum oxide has been identified as $\mathrm{PtO}_{2}$, probably hydrated ${ }^{33}$. The reference electrode was a hydrogen electrode (HE) in the same solution studied or a mercury (I) sulfate electrode $\left(\mathrm{Hg} / \mathrm{Hg}_{2} \mathrm{SO}_{4}, 0.5 \mathrm{M} \mathrm{H}_{2} \mathrm{SO}_{4},+0\right.$. $695 \mathrm{~V}$ vs. $\mathrm{HE}$ at $30^{\circ} \mathrm{C}$ ).

Sulfuric acid solution $(0.5 \mathrm{M})$ was prepared from reagent grade chemicals (supplied from Wako Pure Chemical Ind. Ltd.) and twice- 


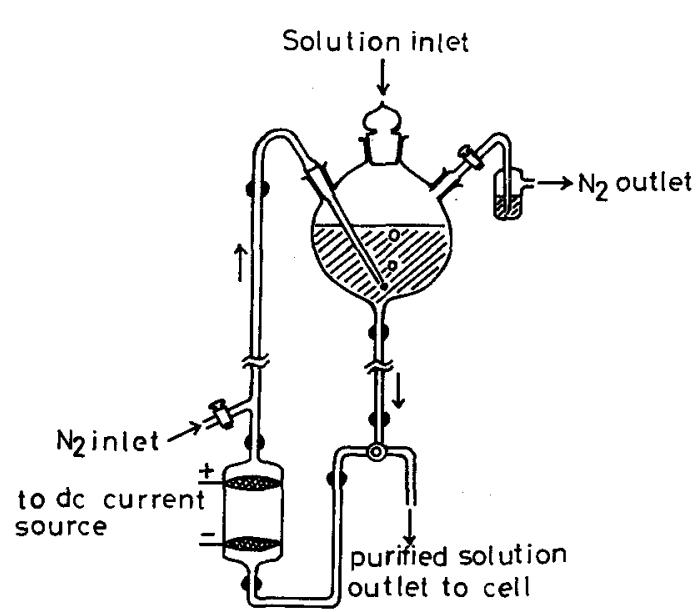

Fig. 1 Assembly for the electrochemical purification of solution

distilled water. The electrochemical procedure was adopted to purify the solution. The purification vessel, illustrated in Fig. 1, is a modified type of the apparatus reported by Damjanovic et $a l .{ }^{4)}$. This is made of Pyrex glass with Teflon stopcocks and Uni-tubes. The electrochemical purification was carried out by passing a constant current of $1 \mathrm{~mA} / \mathrm{cm}^{2}$ between two platinum gauzes in the vessel for over $48 \mathrm{~h}$. All systems including gases used in this study were prepurified by the same procedures as employed in the previous work ${ }^{3}$.

Polarization data presented here are those obtained after waiting for $3 \mathrm{~min}$ at each point of measurement in $\mathrm{O}_{2}$-saturated, bubbling solutions. Measuring circuits and procedures are described previously ${ }^{3)}$.

\section{Results and Discussion}

Polarization characteristics-Anodic and cathodic polarization characteristics of the Pt oxide electrode were measured under galvanostatic and potentiostatic conditions. Figure 2 shows the polarization curve obtained galvanostatically. Such overvoltage data were well reproducible on the $\mathrm{Pt}$ oxide electrode. A very similar curve to this was also obtained under potentiostatic conditions. In the anodic region, one Tafel line with the slope of $0.113 \mathrm{~V} / \mathrm{dec}$ was observed at least over 4 decades. For more than ten runs with different electrodes, the anodic Tafel slopes

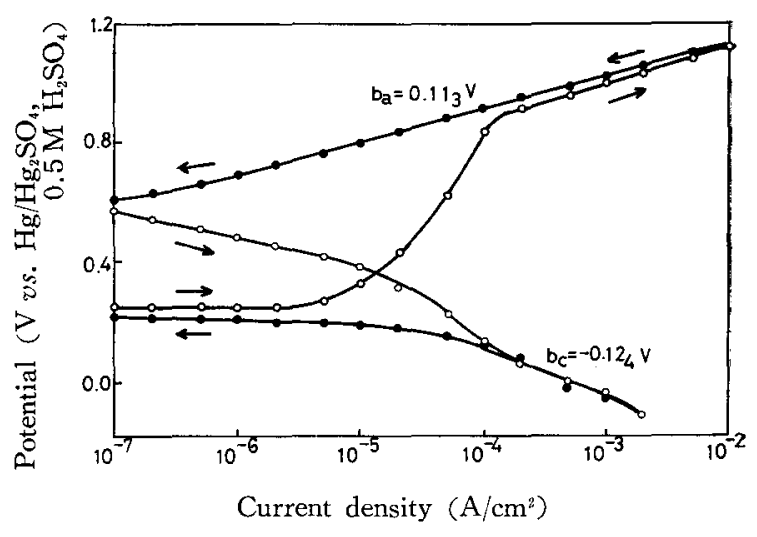

Fig. 2 Anodic and cathodic polarization curves obtained galvanostatically on Ti-supported $\mathrm{Pt}$ oxide electrode in $\mathrm{O}_{2}$-saturated $0.5 \mathrm{M} \mathrm{H}_{2}$ $\mathrm{SO}_{4}$ solution at $30^{\circ} \mathrm{C}$

The arrows give direction of polarization, and open symbol represents data obtained with increasing current and filled symbol those with decreasing current

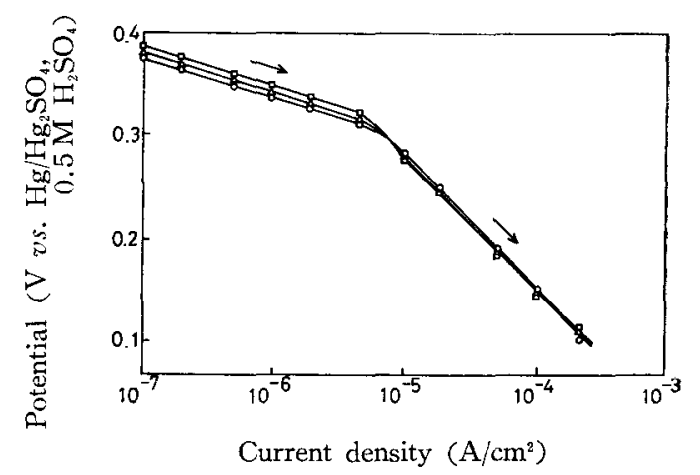

Fig. 3 Reproducibility of cathodic polarization curves obtained galvanostatically on Ti-supported $\mathrm{Pt}$ oxide electrode, in $\mathrm{O}_{2}$-saturated $0.5 \mathrm{M} \mathrm{H}_{2} \mathrm{SO}_{4}$ solution at $30^{\circ} \mathrm{C}$

$$
\bigcirc: 1 \mathrm{st}, \square: 2 \mathrm{nd}, \triangle: 3 \mathrm{rd} \text { cycle }
$$

agreed with the mean value of $0.113 \mathrm{~V} / \mathrm{dec}$ within $\pm 5 \mathrm{mV} / \mathrm{dec}$. On the other hand, the cathodic Tafel slope was determined to be $-0.124 \mathrm{~V} / \mathrm{dec}$ from the cathodic polarization curves measured separately (Fig.3). Using the observed anodic and cathodic Tafel slopes, the stoichiometric number, $\nu$, was calculated to be 3.9 from Parsons' equation ${ }^{5)}$. However, the $\nu$ value is reliable the only case if the anodic and the cathodic processes have a common activated 


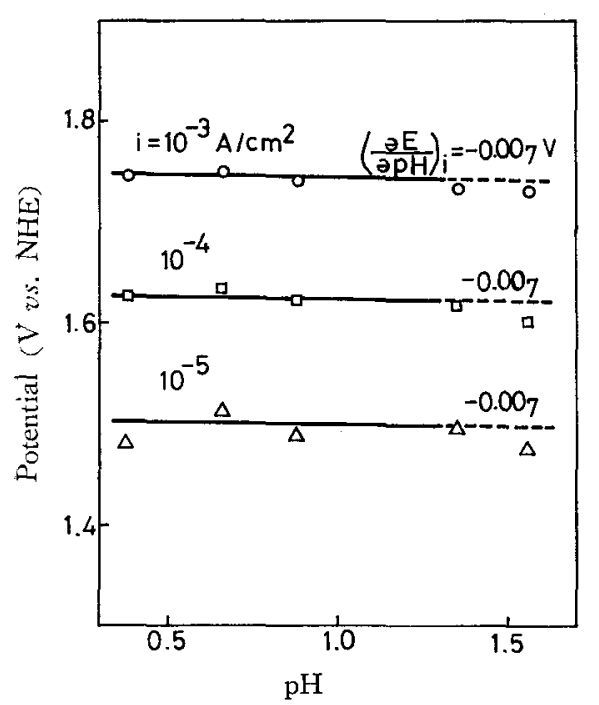

Fig. $4 \mathrm{pH}$ dependence of anodic potential at different current densities in $\mathrm{O}_{2}-$ saturated $\mathrm{H}_{2} \mathrm{SO}_{4}$ solutions at $30^{\circ} \mathrm{C}$

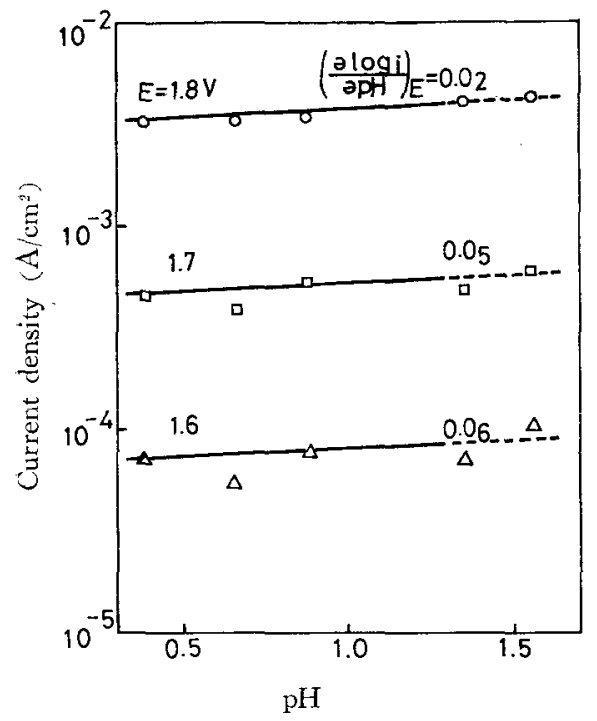

Fig. $5 \mathrm{pH}$ dependence of current density at different anodic potentials in $\mathrm{O}_{2}-$ saturated $\mathrm{H}_{2} \mathrm{SO}_{4}$ solutions at $30^{\circ} \mathrm{C}$

complex in the rate-determining reaction, as pointed out by Parsons. This seems to be the case since extrapolated anodic and cathodic Tafel lines intersected at the reversible oxygen potential (i.e. $0.53 \mathrm{~V}$ vs. $\mathrm{Hg}_{2} \mathrm{Hg}_{2} \mathrm{SO}_{4}, 0.5 \mathrm{M} \mathrm{H}_{2} \mathrm{SO}_{4}$ at $30^{\circ} \mathrm{C}$ ).

Dependence of overpotential on $\mathrm{pH}-$ The concentration of the hydrogen ions in the solution was adjusted by mixing $0.5 \mathrm{M} \mathrm{H}_{2} \mathrm{SO}_{4}$ and $0.5 \mathrm{M} \mathrm{K}_{2} \mathrm{SO}_{4}$ both of which were preelectrolyzed over $48 \mathrm{~h}$. The $\mathrm{pH}$ values were measured by reading the potential difference between $\mathrm{HE}$ and S.C.E. in the test solutions. Anodic polarization measurements were carried out in these solutions. From the results, potentials at constant current densities are replotted in Fig. 4 as a function of $\mathrm{pH}$ of the solution. Figure 5 shows the plots of current densities at constant potentials against $\mathrm{pH}$ values. The observed values of the slopes are indicated in the figures. These lead us to the conclusion that the anodic polarization curves, or the current density and the potential, are independent on $\mathrm{pH}$ of the solution.

Reaction mechanism-On the basis of above experimental results, the overall current density for the anodic evolution of oxygen in the acidic solution can be formulated as

$$
i=n F k \exp \left(\frac{F}{2 R T} E\right)
$$

Any one of the mechanisms proposed by Damjanovic et al. ${ }^{6}$ satisfies eq. (1) if the primary water discharge is the rate-determining step, or

$$
\mathrm{S}+\mathrm{H}_{2} \mathrm{O} \longrightarrow \mathrm{SOH}+\mathrm{H}^{+}+\mathrm{e}^{-}
$$

In this case, the mechanistic parameters deduced theoretically are

$$
\begin{aligned}
& \left(-\frac{\partial E}{\partial \log i}\right)_{a_{\mathrm{F}}{ }^{+}}=2.303\left(\frac{R T}{\beta F}\right) \\
& =2.303 \frac{2 R T}{F} \quad(\beta=1 / 2) \\
& \left(\frac{\partial E}{\partial \log a_{\mathrm{H}}{ }^{+}}\right)_{i}=-\left(\frac{\partial E}{\partial \mathrm{pH}}\right)_{i}=0
\end{aligned}
$$

and

$$
\left(\frac{\partial \log i}{\partial \log a_{\mathrm{H}}{ }^{+}}\right)_{E}=-\left(\frac{\partial \log i}{\partial \mathrm{pH}}\right)_{E}=0
$$

Based on the $\nu$ value of 3.9 , the possible paths are (i) the oxide path, (ii) the hydrogen peroxide path and (iii) the metal peroxide path. Of these three, however, the oxide path is more probable at this stage of the work, since it is unlikely that peroxides are produced at the anode during the evolution of oxygen ${ }^{7,8)}$.

The calculated and found values of mechanistic parameters are summarized in Table 1 , with an assumption of $\beta$ being $1 / 2$.

Temperature dependence of overpotential - The anodic polarization curves were measured at various temperatures of ca. $25^{\circ}$ to $45^{\circ} \mathrm{C}$. For comparison, such measurements were also 
Table 1 Mechanistic parameters for the anodic evolution of oxygen on Ti-supported $\mathrm{Pt}$ oxide electrode in $0.5 \mathrm{M} \mathrm{H}_{2} \mathrm{SO}_{4}$

\begin{tabular}{c|c|c}
\hline \hline $\begin{array}{l}\text { Mechanistic } \\
\text { parameters }\end{array}$ & Theoretical* & Experimental \\
\hline$\left(\frac{E}{\log i}\right)_{a_{\mathrm{H}}}$ & $2.303(2 R T / F)$ & $0.113 \mathrm{~V}$ \\
\hline$\left(\frac{E}{\log a_{\mathrm{H}^{+}}}\right)_{i}$ & 0 & $0.007 \mathrm{~V}$ \\
\hline$\left(\frac{\log i}{\log a_{\mathrm{H}^{+}}}\right)_{E}$ & 0 & -0.04 \\
\hline$\nu$ & 4 & 3.9 \\
\hline
\end{tabular}

$* \beta$ is assumed to be 0.5

carried out at a smooth platinum electrode. This electrode was pretreated as follows: (i) polished with emery papers, (ii) immersed in aqua regia for one day, (iii) degreased by boiling in mixed solution of $\mathrm{NaOH}$ and $\mathrm{Na}_{2} \mathrm{CO}_{3}$, and (iv) cleaned by boiling in twice-distilled water.

The activation energies were calculated from constant over a wide range of potential or overpotential investigated. The latter fact suggests that the reaction mechanism does not change with overpotential : this point greatly differs from the result observed in alkaline solutions where it was supposed that the first step or the discharge of $\mathrm{OH}^{-}$ion is rate-determining at high $\eta$ and the second step or the followed chemical step becomes the rate--determining step at low $\eta$. Furthermore, it seems most likely that the value of activation energy observed in the acidic solution is approximately the same as that observed only at high $\eta$ in the alkaline solution. For both cases, the overall reaction is controlled by the first step or the step where adsorbed $\mathrm{OH}$ radicals are formed.

The results obtained in the present study strongly suggest that the anodic evolution of oxygen on a smooth $\mathrm{Pt}$ electrode also proceeds by the same mechanism as that proposed for the $\mathrm{Pt}$ oxide electrode : it may proceed via the formation of surface oxides, e.g. $\mathrm{PtO}_{2}$ or probably some platinum oxides in higher oxidation states.

$<$ E468 $>$ (Received Jun. 16,1976)

Table 2 Activation energy of oxygen evolution reaction in $0.5 \mathrm{M} \mathrm{H}_{2} \mathrm{SO}_{4}$

\begin{tabular}{l|c|c|c|c|c}
\hline \multirow{2}{*}{$\begin{array}{c}E \\
\text { vs. HE) }\end{array}$} & \multicolumn{2}{|c|}{$\Delta \mathrm{H}(\mathrm{E})(\mathrm{kcal} / \mathrm{mole})$} & \multicolumn{2}{|c}{$\Delta \mathrm{H}(\eta)(\mathrm{kcal} / \mathrm{mole})$} \\
\cline { 2 - 5 } & $\mathrm{Pt}$ & $\mathrm{Pt}$ oxide & $(\mathrm{V})$ & $\mathrm{Pt}$ & $\mathrm{Pt}$ oxide \\
\hline 1.5 & & 11.9 & 0.4 & & 11.9 \\
1.6 & & 11.5 & 0.5 & & 12.7 \\
1.7 & & 11.0 & 0.6 & 12.3 & 12.9 \\
1.8 & & 10.7 & 0.7 & 13.7 & \\
1.9 & \multirow{2}{*}{10.5} & & 0.8 & \\
\hline
\end{tabular}

the following two equations :

$$
\begin{array}{r}
\Delta \mathrm{H}(\mathrm{E})=-2.303 R\left[\frac{\partial \log i}{\partial(1 / T)}\right]_{E} \\
\quad(\mathrm{cal} / \mathrm{mole})
\end{array}
$$

at constant potential and

$$
\begin{gathered}
\Delta \mathrm{H}(\eta)=-2.303 R\left[\frac{\partial \log i}{\partial(1 / T)}\right]_{\eta}+\alpha n F \eta \\
(\mathrm{cal} / \mathrm{mole})
\end{gathered}
$$

at constant overpotential. Plots of $\log i$ against $1 / T$, according to eqs. (6) and (7), gave linear lines. The calculated $\Delta \mathrm{H}(\mathrm{E})$ and $\Delta \mathrm{H}(\eta)$ are given in Table 2.

The activation energy obtained at the Pt oxide electrode was not much different from that obtained at the $\mathrm{Pt}$ electrode, and was nearly
References :

1) J.W. Schultze, K.J. Vetter, Electrochim. Acta 18, 889 (1973); Ber. Bunsenges. Physık. Chem. 77, 945 (1973).

2) A. Damjanovic, A.T. Ward, M. O'Jea, J. Electrochem. Soc. 121, 1186 (1974).

3) C. Iwakura, K. Fukuda, H. Tamura, Electrochim. Acta 21, 501 (1976).

4) A. Damjanovic, M.A. Genshaw, J. O'M. Bockris, J. Electrochem. Soc. 114, 466 (1967).

5) R. Parsons, Trans. Faraday Soc. 47, 1332 (1951).

6) A. Damjanovic, A. Dey, J. O'M. Bockris, Electrochim. Acta 11, 791 (1966).

7) O.J. Walker, J. Weiss, Trans. Faraday Soc. 31, 1011 (1935).

8) J.A.V. Butler, W.M. Leslie, ibid. 32, 435 (1936). 